Supplement of Solid Earth, 10, 1685-1705, 2019

https://doi.org/10.5194/se-10-1685-2019-supplement

(C) Author(s) 2019. This work is distributed under

the Creative Commons Attribution 4.0 License.

(c) (i)

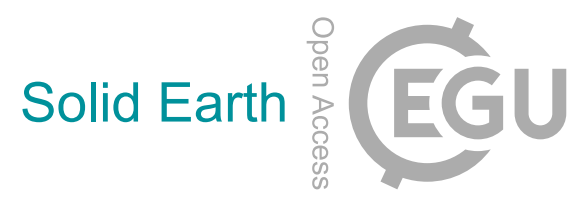

Supplement of

\title{
Subsurface characterization of a quick-clay vulnerable area using near-surface geophysics and hydrological modelling
}

Silvia Salas-Romero et al.

Correspondence to: Silvia Salas-Romero (silvia.salas_romero@geo.uu.se)

The copyright of individual parts of the supplement might differ from the CC BY 4.0 License. 
Table S1. Main processing steps applied to both land and river seismic data.

\begin{tabular}{|c|c|}
\hline Step & Parameters \\
\hline \multicolumn{2}{|c|}{ Land reflection seismic data } \\
\hline 1 & Read 0.5 s SEG-Y data \\
\hline 2 & Zero-time correction \\
\hline 3 & Vertical shot stacking (lines 2b, 6 and 7) \\
\hline 4 & Merge lines from 2011 and 2013 (lines 2 and $2 b$, and lines 5 and 5b) \\
\hline 5 & Extract and apply geometry: CDP spacing $2 \mathrm{~m}$ and $10 \mathrm{~m}$ (line 5-5b wireless) \\
\hline 6 & Trace editing \\
\hline 7 & First break picking: automatic picking and manually corrected \\
\hline 8 & Elevation static corrections: datum $20-25 \mathrm{~m}$ and replacement velocity $1500 \mathrm{~ms}^{-1}$ \\
\hline 9 & $f-k$ filter (line $5-5 b$ wireless) \\
\hline 10 & Wiener deconvolution: gap 10-15 ms \\
\hline 11 & $\begin{array}{l}\text { Band-pass filter: 40-60-200-250 Hz (lines } 6 \text { and 7), 40-60-180-200 Hz (line 2-2b), 70-80-260-280 Hz (line } \\
\text { 5-5b cabled) and 30-60-180-200 Hz (line 5-5b wireless) }\end{array}$ \\
\hline 12 & Spectral whitening: $70-80-180-200 \mathrm{~Hz}$ (line $5-5 \mathrm{~b}$ cabled) and 70-80-200-220 Hz (line 5-5b wireless) \\
\hline 13 & Top mute using first breaks \\
\hline 14 & Surgical mute (line $5-5 \mathrm{~b}$ wireless) \\
\hline 15 & Airwave mute \\
\hline 16 & AGC: $70-500 \mathrm{~ms}$ \\
\hline 17 & Velocity analysis \\
\hline 18 & Residual static corrections (lines 6 and 7) \\
\hline
\end{tabular}


20

21

23

24

25

26

River reflection seismic data

1

2

3

4

6

7

8

6

7

8

Stack

Trace balance

AGC: $100 \mathrm{~ms}$

Stack

Top mute

Trace balance

Band-pass filter: 20-40-150-170 Hz (lines 6 and 7), 50-60-150-170 Hz (line 2-2b) and 30-40-110-130 Hz (line5-5b wireless)

Post-stack deconvolution (line 5-5b wireless)

$f-x$ deconvolution

$f-k$ filter (lines 6 and 7)

Time-to-depth conversion using constant velocity of $1500 \mathrm{~ms}^{-1}$

Read 0.2 s SEG-Y data

Apply marine geometry

Wiener deconvolution: gap 2-6 ms

NMO corrections: $30 \%$ stretch mute

Post-stack deconvolution

$f-x$ deconvolution

Time-to-depth conversion using constant velocity of $1500 \mathrm{~ms}^{-1}$ 

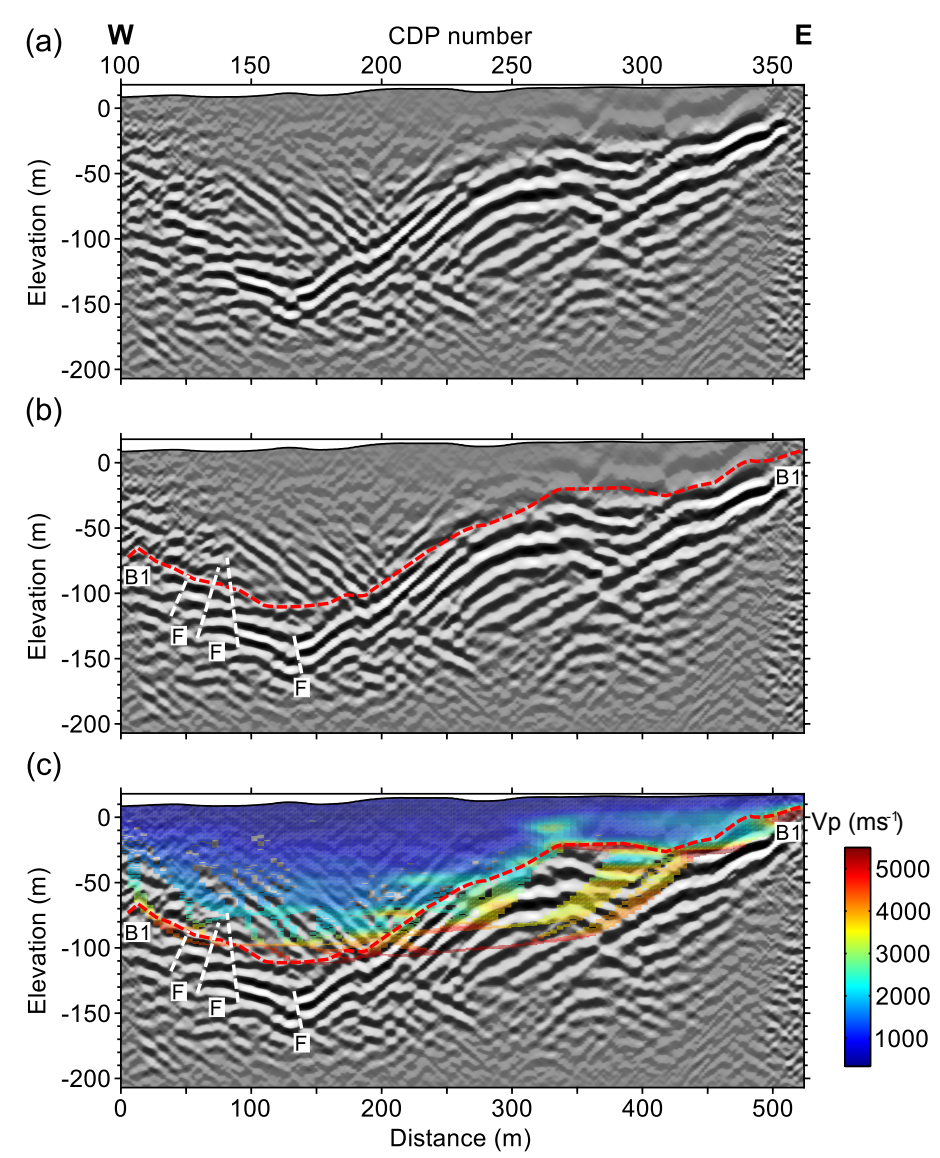

Figure S1. Onshore datasets for line 6. (a) Reflection seismic processing results. (b) Interpreted seismic section, with only a major reflection, B1, identified from the bedrock (dashed red line). At different positions, several fractured or disturbed materials (F) are also delineated using a dashed white line. (c) P-wave refraction tomography model (Wang et al., 2016) superimposed on the interpreted seismic section illustrating consistency between the two independent methods. 


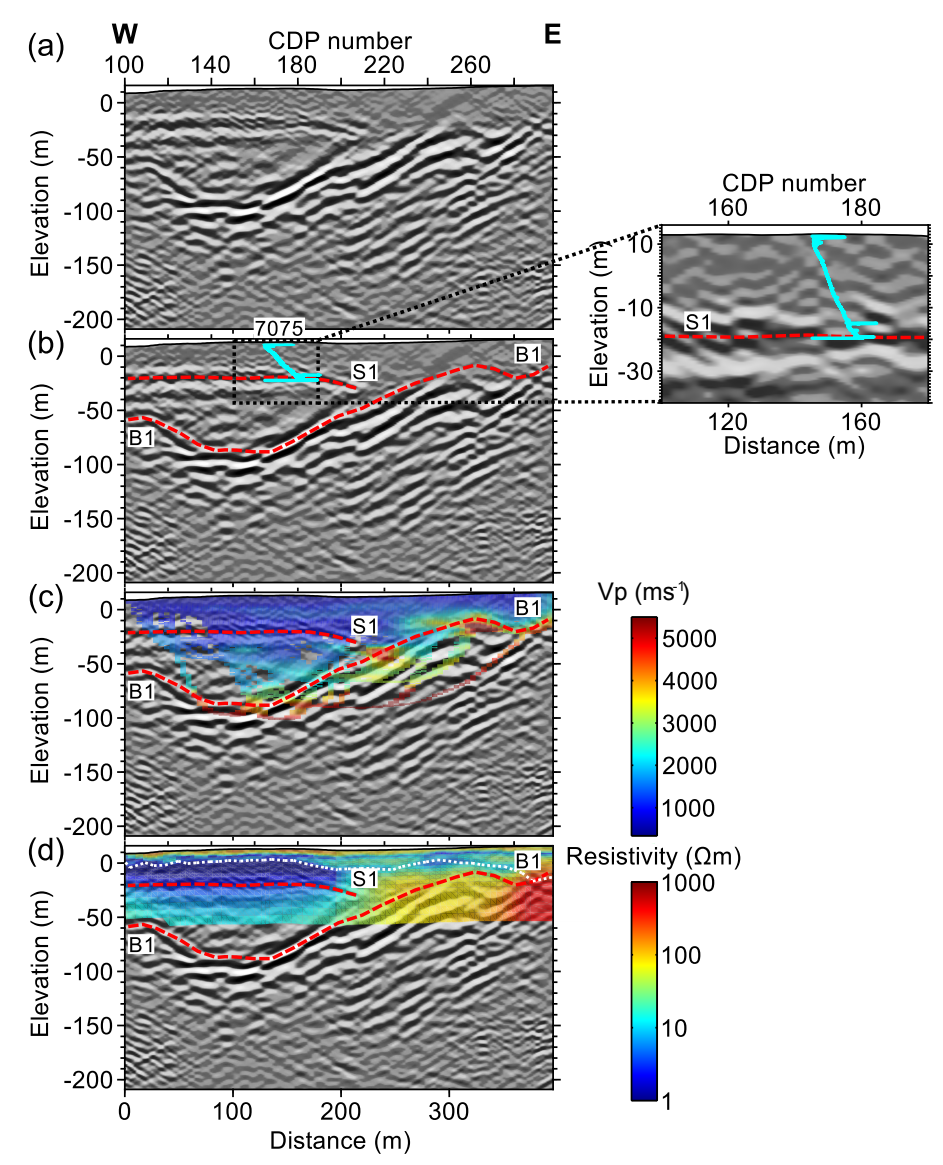

Figure S2. Onshore datasets for line 7. (a) Reflection seismic processing results. (b) Interpreted seismic section including total sounding data (BGA, 2018) from borehole 7075 (ranging from 0 to $14 \mathrm{kN}$ ) in blue. S1 (top of the coarse-grained materials) and B1 (top of the bedrock) represented by dashed red lines. (c) P-wave refraction tomography model (Wang et al., 2016) superimposed on the interpreted seismic section. (d) RMT resistivity results (Wang et al., 2016) superimposed on the interpreted seismic section. The dashed white line indicates the depth above which the results are considered of higher confidence.

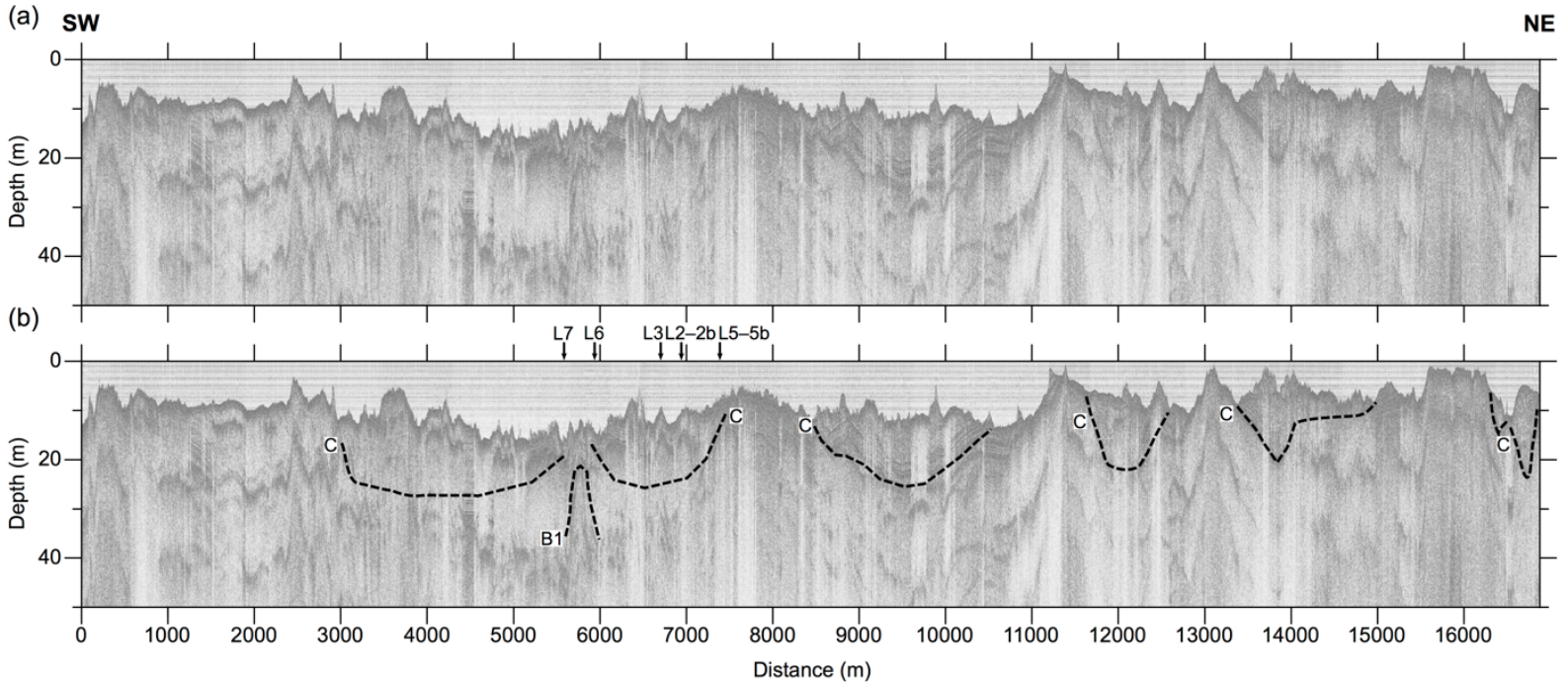

Figure S3. Processing results of the single-channel (3.5 kHz echo sounder) river seismic data (C SGU). (a) Seismic processed section. (b) Interpreted seismic section. C (filled channels) and B1 (top of the bedrock) represented by dashed black lines. The positions of the land seismic lines that intersect this line are indicated on top of the section. Scale $1 \mathrm{H}: 57 \mathrm{~V}$. 

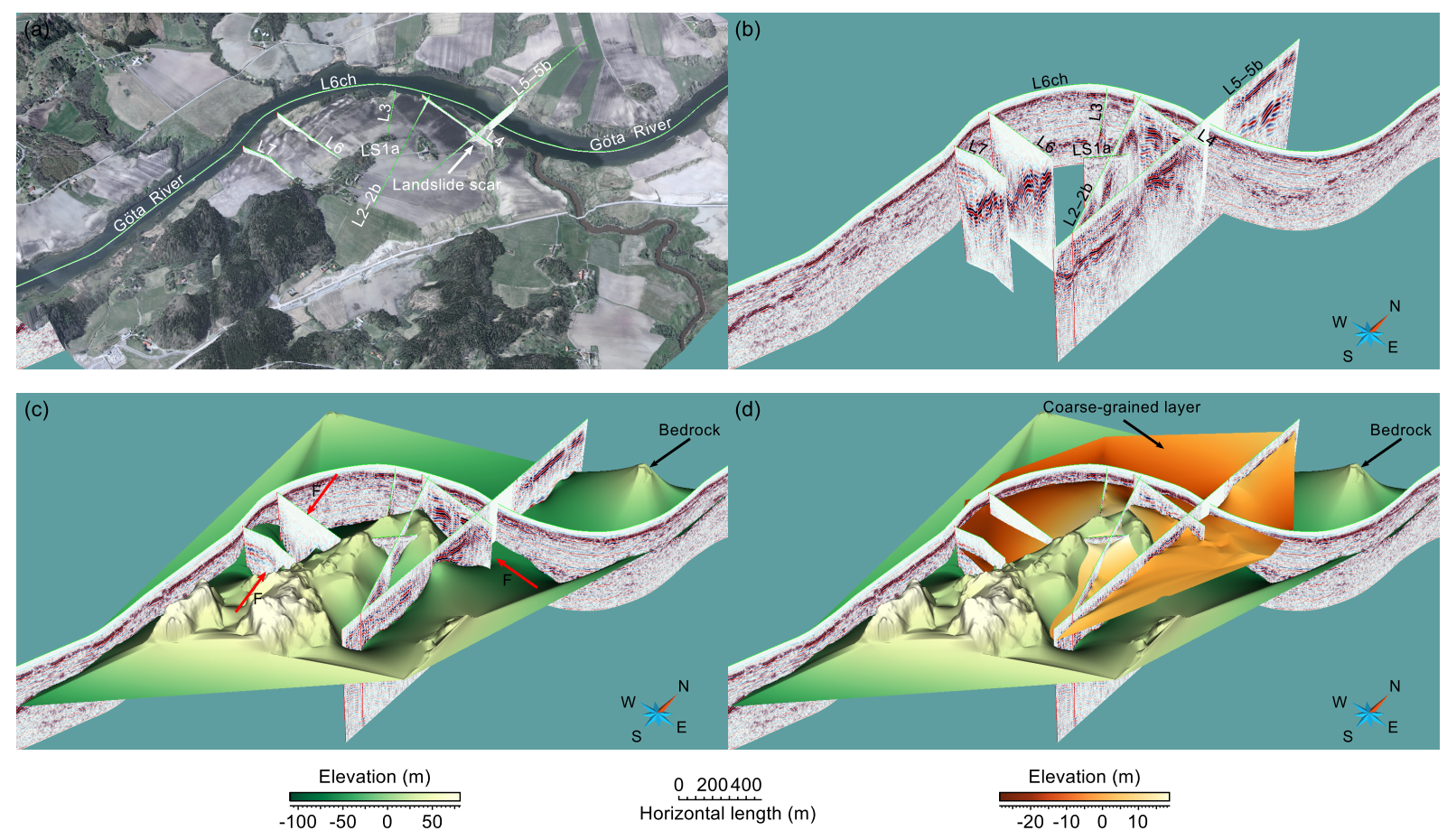

Figure S4. 3-D modelling of the subsurface at the survey site (south view). (a) Aerial photo projected on the lidar elevation surface (C Lantmäteriet) of the study area with the positions of the land and river seismic lines along the Göta River. (b) 3-D view of the land and river seismic processed lines. (c) Elevation of the bedrock surface (F indicates the position of interpreted faults, also observed in Fig. 2a). (d) Elevation of the coarse-grained layer and bedrock surfaces.

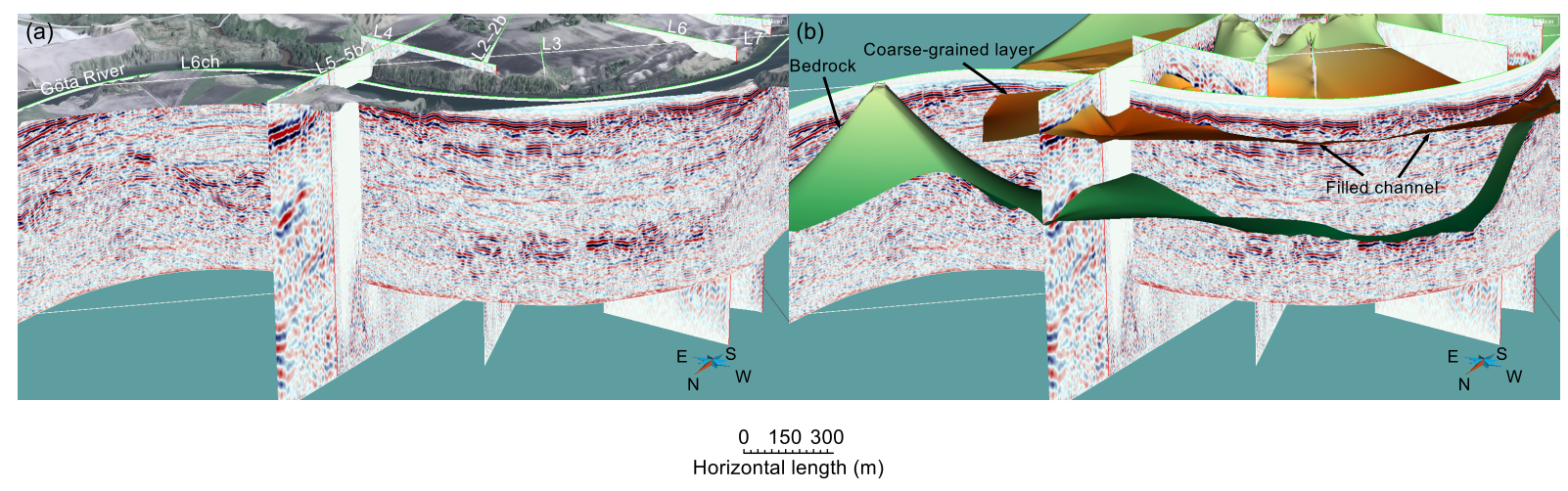

Figure S5. 3-D views of the seismic data and key surfaces in the study area. (a) Aerial photo projected on the lidar elevation surface ( Lantmäteriet) with the positions of the land and river seismic lines along the Göta River. (b) Elevation of the coarsegrained layer and bedrock surfaces. Note the coincidence of the coarse-grained layer surface with the delineation of one of the filled channels (see Figs. S3, 7 and 8). Observe also the undulated bedrock surface between lines 6 and 7 located on the right side of the figure. See elevation values for both surfaces in Fig. S4. 
Table S2. Hydrological measurements in or near the coarse-grained layer (BGA, 2018; Salas-Romero et al., 2016).

\begin{tabular}{|c|c|c|c|c|c|c|c|}
\hline Name & $\mathrm{X}(\mathrm{m})$ & $\mathrm{Y}(\mathrm{m})$ & Pressure $(\mathrm{m})$ & $\mathrm{Z}(\mathrm{m})$ & $\begin{array}{c}\text { Vertical } \\
\text { hydraulic } \\
\text { gradient at the } \\
\text { coarse-grained } \\
\text { layer }\end{array}$ & Notes & $\begin{array}{l}\text { In the model } \\
\text { domain }\end{array}$ \\
\hline BH1 & 331767.66 & 6454139.96 & 23 & -10 & - & Winter & Yes \\
\hline $\mathrm{BH} 2$ & 331827.11 & 6454582.84 & 11 & $? ?$ & - & Winter & Yes \\
\hline $\mathrm{BH} 3$ & 331991.53 & 6454378.35 & 14.5 & -20 & - & Winter & Yes \\
\hline 7052 & 332189.98 & 6454719.86 & 9.4 & -21 & Up & Artesian & No \\
\hline 7053 & 332198 & 6454690.07 & 8.1 & -10.4 & Up & - & No \\
\hline 7054 & 332221.03 & 6454609.99 & 8.3 & -9.1 & Up & - & No \\
\hline 7063 & 331583.73 & 6454638.19 & 7.7 & -21.9 & Up & - & Yes \\
\hline 7064 & 331595.99 & 6454609.98 & 10.1 & -12.2 & Up & $\begin{array}{c}\text { Seasonally } \\
\text { artesian }\end{array}$ & Yes \\
\hline 7065 & 331619.02 & 6454550 & 11.2 & -10.6 & - & - & Yes \\
\hline 7073 & 331051.03 & 6453638.89 & 10.3 & -26.2 & Up & Artesian & No \\
\hline 7075 & 331179.6 & 6453643.24 & 12 & -24.8 & Up & - & No \\
\hline
\end{tabular}

Table S3. Hydrological measurements above the coarse-grained layer (BGA, 2018). 


\begin{tabular}{|c|c|c|c|c|}
\hline Name & $\mathrm{X}(\mathrm{m})$ & $\mathrm{Y}(\mathrm{m})$ & Pressure (m) & $\mathrm{Z}(\mathrm{m})$ \\
\hline 7052 & 332189.98 & 6454719.86 & 7.1 & 6 \\
\hline 7052 & 332189.98 & 6454719.86 & 7.4 & 1 \\
\hline 7052 & 332189.98 & 6454719.86 & 7.44 & -2.4 \\
\hline 7053 & 332198 & 6454690.07 & 16.2 & 16.6 \\
\hline 7053 & 332198 & 6454690.07 & 14.1 & 11.6 \\
\hline 7053 & 332198 & 6454690.07 & 11.3 & 4.6 \\
\hline 7053 & 332198 & 6454690.07 & 7.7 & -3 \\
\hline 7054 & 332221.03 & 6454609.99 & 19.9 & 17.9 \\
\hline 7054 & 332221.03 & 6454609.99 & 19.4 & 12.9 \\
\hline 7054 & 332221.03 & 6454609.99 & 15.9 & 5.9 \\
\hline 7054 & 332221.03 & 6454609.99 & 7.5 & -3.7 \\
\hline 7063 & 331583.73 & 6454638.19 & 8.2 & 5.1 \\
\hline 7063 & 331583.73 & 6454638.19 & 6.9 & 0.1 \\
\hline 7063 & 331583.73 & 6454638.19 & 7.3 & -6.9 \\
\hline 7064 & 331595.99 & 6454609.98 & 16.3 & 13.8 \\
\hline 7064 & 331595.99 & 6454609.98 & 15 & 9.8 \\
\hline 7064 & 331595.99 & 6454609.98 & 12.8 & 2.8 \\
\hline 7064 & 331595.99 & 6454609.98 & 10 & -12.2 \\
\hline 7065 & 331619.02 & 6454550 & 18.4 & 15.4 \\
\hline 7065 & 331619.02 & 6454550 & 17.7 & 11.4 \\
\hline
\end{tabular}




\begin{tabular}{lllll}
7073 & 331051.03 & 6453638.89 & 7.7 & 3.8 \\
7073 & 331051.03 & 6453638.89 & 8.2 & -0.2 \\
7073 & 331051.03 & 6453638.89 & 9.6 & -7.2 \\
7075 & 331179.6 & 6453643.24 & 11.9 & 9.3 \\
7075 & 331179.6 & 6453643.24 & 12.8 & 5.3 \\
7075 & 331179.6 & 6453643.24 & 12.6 & -1.7 \\
7056 & 332113.11 & 6454510.08 & 20.2 & 19.3 \\
7060 & 331908.12 & 6454669.9 & 16.4 & 13.3 \\
\hline 7069 & 331408 & 6454520 & 15.4 & \\
\hline
\end{tabular}

